\title{
Study on Interest Game and Allocation Mechanism in Allocation of China's Environmental Management Right
}

\author{
Meng Tao \\ School of Public, Policy \& Management, Tsinghua University, Beijing, China \\ Email address: \\ mengtao@mail.tsinghua.edu.cn \\ To cite this article: \\ Meng Tao. Study on Interest Game and Allocation Mechanism in Allocation of China's Environmental Management Right. International \\ Journal of Environmental Protection and Policy. Vol. 5, No. 4, 2017, pp. 54-60. doi: 10.11648/j.ijepp.20170504.12
}

Received: April 13, 2017; Accepted: May 5, 2017; Published: July 5, 2017

\begin{abstract}
China's environmental protection issue is increasingly highlighted with its rapid economic development. Related theories and practices demonstrate that both market and government failures exist in the environmental governance issue. At present, the core issue for China's environmental governance is the allocation of environmental management right between governments, non-governmental organizations, enterprises, and communities. The local governments function as the link among them. It is very important to study the Central Government's mechanism design in the allocation of environmental management right and the local governments' behavior choice. This paper analyzes the principal-agent relation between both the Central Government and local governments, and studies their selections respectively in symmetric and asymmetric information conditions. By analyzing, it holds that in the case of satisfying a certain constraint conditions, the Central Government can ensure that local governments can comply with more strictly the environmental regulation mechanism by giving them an excessive payment, whereas the local governments should truthfully select an optimal effort level.
\end{abstract}

Keywords: Environmental Management Right, Interest Game, Allocation Mechanism Design

\section{Introduction}

China has made the achievements that amazed the world with more than 30 years of its rapid economic growth. However, this is followed by the increasingly severe environment problem. According to a report published by Yale University in 2016, China ranked $109^{\text {th }}$ in 2016 world environmental performance indexes of 180 countries and regions, and took the last but one in air quality. The environmental problem has become a focus affecting sustainable and sound development of China's economy and society. The Chinese Government always pays high attention to environmental problem, and puts in a great deal of manpower, material resources and financial resources. However, China's environmental condition is not obviously turned round yet. With the public's environmental awareness constantly increasing, the environmental management will become an inevitable choice in realizing regional economic development and building a harmonious society.

There are increasingly in-depth studies on environmental management in academic circles. These provide certain theoretical bases for the environmental regulation from management theories to the establishment of environmental management systems. Some foreign scholars mainly analyzed the problems and causes from the perspectives of externalities and collective action failure in international environmental management, proposed that the international mechanism should be established based on the internalization theory, and the reform to existing management system should be carried by the cooperation between organizations. In the related studies at home, some scholars studied the functions of social organizations' joint participation in remedying local governments' environmental management failure and building their environmental cooperative governance network. By explaining the relation of national and individual environmental management rights, some scholars held that the national environmental right should stand a leading position, but the focus of environmental management should gradually shift to the individual environment right. From the perspective of governments' environmental regulations, some scholars analyzed the enterprises' endogenous governance motivations and the external individual participation in governments' environmental management 
regulations. Other scholars studied non-governmental organizations' participation in environmental management from different perspectives. Nevertheless, there are seldom studies on the allocation mechanism of environmental management right at present, but this allocation mechanism is just a key to handle the issue by the joint participation of the whole society in the environmental governance.

\section{Analysis on the Interest Subjects in Environmental Management Right Balanced Allocation}

Generally speaking, the environmental management is involved in four interested parties: government, nongovernment, enterprise and the public. In order to realize the dynamic balance and gain an optimal growth path in the four parties' right, as well as keep a good relation between economic development and environmental quality improvement, the key is to well coordinate the game relation of the four parties, so that the environmental management right comes to a balanced allocation among the four interested parties. By this way, the purpose is achieved for mutual supervision, coordination, interaction and mutual promotion. As a result, the environmental management develops well towards a right direction in the great economic environment of all interested parties.

In reality, however, local governments can implement the strict environmental management measures according to the requirement of optimal growth path, and seek for a coordinate balance between economic growth and ecological environment. Even if so, with a certain time lag, they may not be conscious of any growth advantage in the optimal economic growth path in their ruling period. In the initial stage of economic growth, they may see that the gap is enlarged gradually at total social welfare levels gained by administration respectively according to the optimal growth path and self-utility maximization. Owing to some issues in current China's environmental management system, a lot of local governments often pursue the short-term profit maximization. Thus, in current environmental management system and administrative performance evaluation system, these governments often give up the optimal growth path, and instead, they choose an ordinary growth path of the short-term profit maximization.

Therefore, in order to realize the optimal growth path of total social welfare for constant improvement of environmental quality, a perfect mechanism design should be made as a guarantee. In the mechanism design, the government should assign portion of the environmental management right to non-governmental organizations, enterprises and the public which work at environmental protection. The environmental-protection non-governmental organizations can successfully fulfill their external management coordination, and receive the public" supervision and governments' management. The public can actively participate in safeguarding of legal rights, and the enterprises can take the coordination of internal and external management. Moreover, the local governments conduct environmental management efficiently in pursuing the long-term profit maximization, and make the environmental management right to be well allocated in the end. In the whole environmental management, both Central Government's mechanism design and local governments' behavior choice are more important.

Under the current environmental management system, the management authority for environmental protection is controlled by governments at all levels for the most part. Without governments' support and permission, non-governmental organizations are unable to get the authority to manage and supervise environmental protection, the public can't get security and operability for their environmental rights and interests, and the enterprises have no initiatives and capability to carry out high-quality environmental management. So, a mechanism should be designed initiatively by the Central Government based on the characteristics of economic changes in the development stage, so that the most of environmental management right controlled by local governments can be allocated rationally to interested parties for the purpose of mutual cooperation, interaction and improvement.

\section{The Central Government's Mechanism Design and Local Governments' Behavior Choice}

Under the government-oriented environmental management system in China, the Central Government is no doubt a natural and efficient mechanism designer. Because of its great restraints and control to local governments' behaviors, the Central Government is undoubtedly playing an important role in the mechanism design.

The game between the Central Government and local governments is set as an principal-agent relation between both the Central Government and local governments. In order to confirm the issue, this paper simplifizes their relation, supposing only one Central Government and one local government are taken into account, and the Central Government has a game with only one local government. However, the mechanism operation formulated by the Central Government is dependent on the actions taken by the Central Government as well as the natural state uncontrolled between the Central Government and local governments. The different actions taken by local government can result in different costs, whereas the Central Government can't observe local governments' actions. For instance, the Central Government stipulates that local governments' environmental protection behavior must be supervised by non-governmental organizations, the public and enterprises; the three parties may participate in their environmental management activities. However, the local governments may comply with above requirements superficially, but actually they may raise one obstacle after another covertly to impose restriction on the 
three environmental management parties to exercise their environmental protection functions. Such covert behavior is often seen through by the Central Government.

Supposing the Central Government sets a mechanism, providing the local governments must be supervised by environmental-protection non-governmental organizations, then it should give these organizations a certain administrative power to supervise local governments' economic and environmental behaviors, and determines the promotion of officials based on local governments' compliance with the mechanism formulated by the Central Government. In the following function, Action $a \in\left[a_{0}, a_{1}\right)$ that the local government may select, and $y$ is used to represent the payment gained by local governments from the Central Government, which can be interpreted as the chance of promotion. So, the local government utility function is established. Supposing the utility function is divisible, then its specific form can be written as:

$$
U(y, a)=u(y)-a u^{\prime}>0, u^{\prime \prime} \leq 0
$$

The local government's reservation utility is recorded as $\bar{U}$, and the utility is defined as follows: If the local government may not comply with the mechanism designed by the Central Government when the utility $\mathrm{U}(\mathrm{y}, \mathrm{a})$ gained by the local government in the mechanism is less than $\bar{U}$, then, the $\bar{U}$ is called the local government's reservation utility, that is to say, this utility is the minimum one gained by the local government when it must comply with the mechanism designed by the Central Government.

The Central Government can't see through the Action $a$ selected by local government, and the degree of local government's compliance is uncertain in the fixed action. The degree of local government's compliance with the mechanism designed by the Central Government is recorded as $\tilde{\mathrm{x}}$, where $\tilde{\mathrm{X}}$ is a random variable, whose distribution function is $\mathrm{F}(\mathrm{x}, \mathrm{a})$ and distribution density function is $\mathrm{F}(\mathrm{x}, \mathrm{a})$. Supposing that $\tilde{\mathrm{x}}$ range is $[\alpha, \beta]$, and it is not related to local government's action $a$, the Central Government's expected utility function will be:

There are two cases of optimal mechanism design taken into account as follows: one is the optimal mechanism design in symmetric information, the other is the one in asymmetric information.

\subsection{Optimal Mechanism Design in Symmetric Information}

Supposing the Central Government can observe the local government's Action $a$, then, the Central Government is intended to maximize its own expected utility in the participation constraint:

$$
\begin{gathered}
\max _{a, y} E[V(\tilde{x}-y(\tilde{x}))] \\
\text { s.t. } E[u(y(\tilde{x}))-a] \geq \bar{U}
\end{gathered}
$$

The Lagrange function is:

$$
L=\int_{\alpha}^{\beta} V[x-y(x)] f(x, a) d x+\lambda\left\{\int_{\alpha}^{\beta} u[y(x)] f(x, a) d x-a-\bar{U}\right\}
$$

The first order necessary condition is:

$$
\frac{V^{\prime}[x-y *(x)]}{u^{\prime}[y *(x)]}=\lambda * \forall x \in[\alpha, \beta]
$$

with:

$$
\int_{\alpha}^{\beta}\{V[x-y *(x)]+\lambda u[y *(x)]\} f(x, a) d x=\lambda *
$$

and:

$$
\int_{\alpha}^{\beta} u(y(x)) f(x, a) d x-a-\bar{U}=0
$$

Because $\mathrm{V}^{\prime}>0$, the participation constraint is constrictive, that is,

$$
\int_{\alpha}^{\beta} u(y(x)) f(x, a) d x-a-\bar{U}=0
$$

Thereby,

$$
\lambda *>0
$$

It is known by above formula that the following expression is established for any two levels $x, x^{\prime} \in[\alpha, \beta]$ designed by the Central Government and complied with by local governments:

$$
\frac{V^{\prime}[x-y *(x)]}{V^{\prime}\left[x^{\prime}-y *\left(x^{\prime}\right)\right]}=\frac{u^{\prime}[y *(x)]}{u^{\prime}\left[y *\left(x^{\prime}\right)\right]} \forall x, \quad x^{\prime} \in[\alpha, \beta]
$$

Pareto risk allocation rule well-known by us: This expression is the marginal rate of substitution is equal between the utilities of the Central Government and local governments in different states; specially, if the Central Government keeps risk neutral, then it is inferred that:

$$
u^{\prime}[y *(x)]=u^{\prime}\left[y *\left(x^{\prime}\right)\right]
$$

But if $\mathrm{u}^{\prime}>0$, then $y *(x)=y *\left(x^{\prime}\right)$, it means the local government can get a unchanged payment in all states, and the Central Government takes all risks by itself.

If both the Central Government and local government are averse of risk, the differential for $x$ is taken, the following formula is got:

$$
-\frac{V^{\prime \prime \prime}}{V^{\prime}}=-\left[\frac{V^{\prime \prime}}{V^{\prime}}+\frac{u^{\prime \prime}}{u^{\prime}}\right] \frac{d y *}{d x}
$$

Both $A_{P}$ and $A_{A}$ represent the Arrow-Pratt absolute risk aversion coefficients of the Central Government and local government respectively, and above formula can be rewritten as:

$$
\frac{d y *}{d x}=\frac{A_{P}}{A_{P}+A_{A}}
$$

If the local government's action is given, then for the Central Government, the optimal payment in symmetric information depends on the relative change of local government and Central Government's degree of risk aversion. 


\subsection{Optimal System Design in Asymmetric Information}

Before the optimal incentive mechanism in asymmetric information is discussed, a specific explanation is made on the way of the influence of local government's Action $a$ on output distribution. This paper has ever supposed that the range $[\alpha, \beta]$ of random variable $\tilde{\mathrm{x}}$ is not related to $a$. Such supposition is to avoid the Central Government's case to be too simple and meaningless in analysis. If not so, the two distribution density functions as shown in Figure 1 can be taken into account: The base corresponding to Action $a^{*}$ is $\left[\alpha\left(\mathrm{a}^{*}\right), \beta\left(\mathrm{a}^{*}\right)\right]$; the base corresponding to another Action $a^{\prime *}$ is $\left[\alpha\left(a^{\prime}\right), \beta\left(a^{\prime}\right)\right]$. Supposing the Central Government expects the local government to select Action $a^{*}$, then as long as the local government selects $a^{\prime}$, both Central Government and local government well know that the probability $\mathrm{F}\left[\alpha\left(\mathrm{a}^{*}\right), \mathrm{a}^{\prime}\right]$ (the dash area in Figure 1) of the compliance level $x$ falling within $\left[\alpha\left(\mathrm{a}^{\prime}\right), \alpha\left(\mathrm{a}^{*}\right)\right]$ is positive. By this, it is ensured that the local governments select $a^{*}$ as long as the Central Government gives the full punishment to the local governments which have the compliance level of $x \in$ $\left[\alpha\left(\mathrm{a}^{\prime}\right), \alpha\left(\mathrm{a}^{*}\right)\right]$, because the local governments would take too big risk.

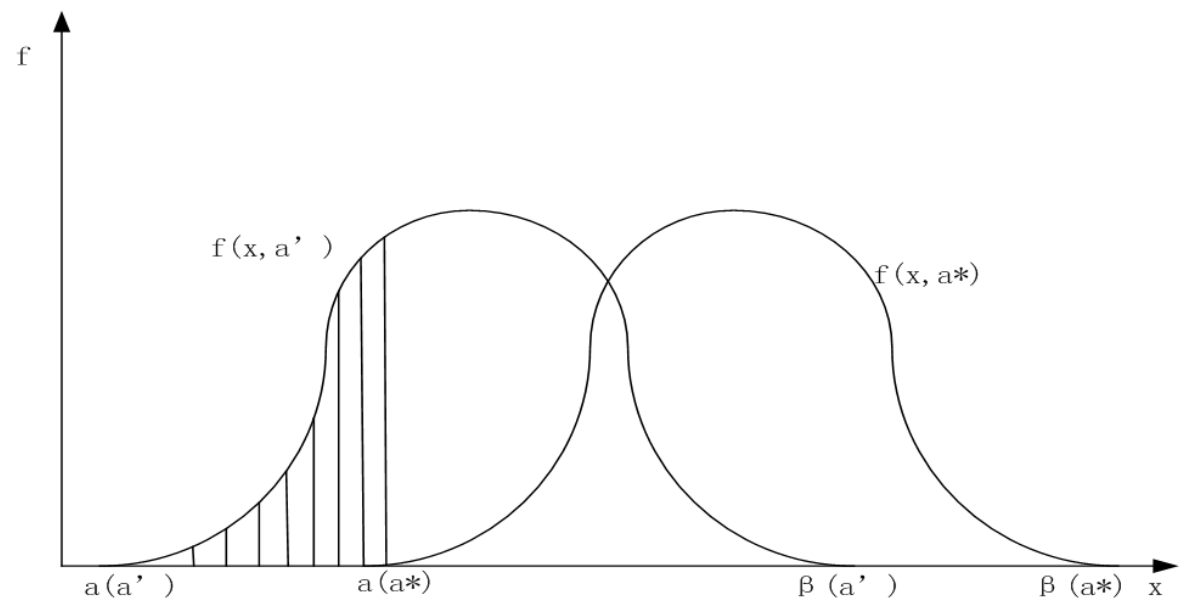

Figure 1. The Central Government's severe punishment mechanism on the different bases.

In the premise of the unchanged base of $\tilde{x}$, it is supposed that the output is increased in the first-order random dominance significance with an increase of $a$, that is to say, $F \_a(x, a) \leqslant 0$, and the strict inequation is available at some $x$ points. In the supposing stage, if $a>a^{\prime}$, then, $F(x, a) \leqslant F(x, a)$, and the strict inequation is available at some $x$ points. $y$ is given, then

$$
\begin{aligned}
& \int_{\alpha}^{\beta} V(x-y) d F(x, a) d x-\int_{\alpha}^{\beta} V(x-y) d F\left(x, a^{\prime}\right) \\
& =\left.V(x-y)\left[F(x, a)-F\left(x, a^{\prime}\right)\right]\right|_{\alpha} ^{\beta}-\int_{\alpha}^{\beta} V^{\prime}(x-y)\left[F(x, a)-F\left(x, a^{\prime}\right)\right] d x \\
& =-\int_{\alpha}^{\beta} V^{\prime}(x-y)\left[F(x, a)-F\left(x, a^{\prime}\right)\right] d x>0
\end{aligned}
$$

The Central Government's expected utility increases with an increase of $a$. So, $a$ is explained as local governments' effort degree.

Now supposing the Central Government can't detect local government's Action $a$, then it gives the payment to the local governments only based on the local governments' compliance with the mechanism level designed and observed finally by the Central Government. Herein the payment is interpreted as the chance of promotion for local government officials. Of course, the Central Government knows that for any a payment proposal $\mathrm{y}(\mathrm{x})$, the local government will select Action $a$ that is fittest to itself. So, the Central Government's question is:

$$
\begin{gathered}
\max _{a, y(x)} \mathrm{E}[\mathrm{V}] \\
\text { s.t. } E[U] \geq \bar{U}(\text { P.C. }) \\
\text { a } \max E[U] \text { (I.C.) }
\end{gathered}
$$

The condition (P. C.) in above formula is the participation constraint, that is, only when the payment given by the Central Government to the local governments is greater than or equal to $\bar{U}$, the local government can comply with the environmental protection supervision mechanism designed by the Central Government; (I. C.) is generally known as an incentive compatibility constraint, and also called a self selection constraint. 
It is difficult to directly analyze above issue, because the incentive compatibility constraint is involved in another maximum value problem. Nothing but in many occasions, it may replace the condition (I. C.) by the first-order necessary condition of the maximum value, on condition that the first-order necessary condition is also a sufficient condition at the same time-This is so-called first-order condition method.

The incentive compatibility constraint is replaced as its first-order necessary condition, the question becomes as follows:

$$
\begin{aligned}
& \max _{a, y(x)} \int_{\alpha}^{\beta} V[x-y(x)] f(x, a) d x \\
& \text { s. t. } \int_{\alpha}^{\beta} u[y(x)] f(x, a) d x-a \geq \bar{U}
\end{aligned}
$$

The Lagrange function can be written as the following simple form:

$$
L=E[V]+\lambda[E[U]-\bar{U}]+\mu \frac{\partial E[U]}{\partial a}
$$

According to the Kuhn-Tucker theorem, both constants $\lambda^{*}$ and $\mu^{*} \geq 0$ exist, so that the first-order condition is available:

$$
\begin{gathered}
\frac{V^{\prime}[x-y *(x)]}{u^{\prime}[y *(x)]}=\lambda *+\mu * \frac{f_{a}(x, a)}{f(x, a)} \forall x \in[\alpha, \beta] \\
\frac{\partial E[V]}{\partial a}+\lambda * \frac{\partial E[U]}{\partial a}+\mu * \frac{\partial^{2} E[U]}{\partial a^{2}}=0
\end{gathered}
$$

It is easily seen by comparing above two formulas that if $\mu^{*}>0$, the optimal mechanism in asymmetric information is proved to impossibly result in the Pareto's effective risk allocation, and at this time, the Central Government can prevail with the local governments to make more efforts (bigger $a$ ) than Pareto's effective level. In fact, the following theorem can be proved to be established:

Theorem: If the agent is averse in risk, then $\mu^{*}>0$ is necessarily available in the conditions in this paper.

The proof of this theorem can refer to Holmstrom (1979) or Shavell (1979).

The meaning of above theorem can be further understood in the political aspect in a special case-local governments' risk neutral. If the Central Government keeps neutral in risk, the Pareto optimal risk allocation requires it to take all risks, and the local governments can obtain an unchanged income. However, if the payment to the local governments doesn't depend on its final compliance level of environmental protection supervision mechanism designed by the Central Government, it will select Action $a$ with a lest effort degree. Hence, in order to avoid the moral risk issue, the optimal incentive mechanism in covert behavior connects the local government's income necessarily with the level of its compliance with environmental protection supervision mechanism.

If local government keeps neutral in risk, the Central Government may simply predetermine its own conservation compliance level $\hat{x}$ in mechanism design, so that local governments can obtain residual claim, and so the local governments gain all total compliance level where $\hat{x}$ is removed: $\bar{x}-\hat{x}$. Because local governments' income depends on its effort level $a$, the incentive compatibility constraint is obviously satisfied, and its specific real meaning is: the Central Government pre-sets a reserved environmental protection compliance level $\hat{x}$, the local governments can obtain the promotion chance level $\tilde{y}$ at an optimal effort level $\tilde{a}$. At this time, the local government may lower its compliance level; it may lower its compliance level to $\bar{x}-\hat{x}$ from $\hat{x}$, so that its effort level $a$ is also reduced accordingly. But by this time, the Central Government allows the local government to obtain higher utility.

Intuitively, this paper wishes the payment function determined $y *(x)$ by the first-order condition is monotonically increasing. Because $\mathrm{V}^{\prime}>0, \mathrm{u}^{\prime}>0$, the necessary and sufficient condition for the $y *(x)$ monotonic increasing is the monotonically increasing of $V[x-y *(x)] /$ $u[y *(x)]$, which is equivalent to Function $\frac{\mathrm{f}_{\mathrm{a}}(\mathrm{x}, \mathrm{a})}{\mathrm{f}(\mathrm{x}, \mathrm{a})}$ to be a monotonic increasing function of $\mathrm{x}$. Thus, in order to ensure the monotonic increasing property, it is necessary to suppose Function $f_{a} / f$ is monotonically increasing to the variable $x$. this is the Monotone Likelihood Ratio Condition. In fact, (1) is derived to $\mathrm{x}$, and it is available as follows:

$$
\frac{d y *}{d x}=\frac{A_{P}}{A_{P}+A_{A}}+\gamma \frac{\partial}{\partial x}\left(\frac{f_{a}}{f}\right)
$$

$A_{P}$ and $A_{A}$ represent the Arrow-Pratt absolute risk aversion coefficients of both Central Government and local government respectively

$$
\gamma=\mu * \mu^{\prime} /\left(A_{P}+A_{A}\right) V^{\prime}>0
$$

When the monotone likelihood ratio condition

$$
\frac{\partial}{\partial x}\left(\frac{f_{a}}{f}\right)>0
$$

is satisfied, even if the Central Government keeps risk neutral $\left(A_{F}=\mathbf{0}\right)$, it is ensured $d y * / d x>0$ that optimal incentive mechanism can meet the most basic principle of "the higher the compliance level with environmental protection mechanism is, the more the promotion chances are".

The monotone likelihood ratio condition can be interpreted intuitively as: the (logarithmic) likelihood function is $\operatorname{lnf}(\mathrm{x}, \mathrm{a})$ in a statistical inference model with an endogenous variable $\mathrm{x}$ and an estimator variable $a$. If the observed value $\mathrm{y}$ and estimated value $\mathrm{a}^{0}$ are given, the bigger the $\ln f$ is, the bigger the probability that $a$ is indeed equal to $\mathrm{a}^{0}$. Hence, the likelihood ratio $\frac{\partial \operatorname{lnf}}{\partial \mathrm{a}}=\mathrm{f}_{\mathrm{a}} / \mathrm{f}$ represents a possible inference that the observed $y$ is from another model with a parameter of $a \neq a^{0}$. This first means that the Central Government necessarily deviates from the Pareto effective allocation in hidden information case. As for the degree of deviation, it 
depends on the likelihood ratio $f_{a} / f$ : the bigger, the $f_{a} / f$ is, the greater the deviation is.

For local government's compliance level $\mathrm{x}$, if $\mathrm{f}_{\mathrm{a}} / \mathrm{f}$ is bigger, the Central Government can have a great confidence to infer that the deviation of $\mathrm{x}$ and expected compliance level is from local government's opportunistic practice or the natural fluctuation of random variable though the expression value $\tilde{x}$ of compliance level is random. Therefore, the payment level gained by local government even more depends on the level of its compliance with the environmental protection mechanism formulated by the Central Government. Conversely, if $f_{a} / f$ is less, the Central Government is hard to distinguish the two factors-local government's opportunistic behavior and natural random fluctuation. In such case, it may be a best choice that the Central Government offers a retained income to local governments directly, and completely gives up the incentive to the local governments. This is a reluctant action, but it is the same with the payment form of Pareto risk optimal allocation.

It is seen from above model analysis that as long as the appropriate mechanism design proposal is selected, the Central Government can ensure the environmental protection supervision rules designed by it can be executed smoothly even if $f_{a} / f$ is as big.

\subsection{Effectiveness of the First-Order Condition Method}

In the first-order condition method, this paper displaces the incentive compatibility constraint

$$
E\left[U(y(\tilde{x}), a] \geq E\left[U ( y ( \tilde { x } ) , a ^ { \prime } ] \forall a \in \left[\begin{array}{ll}
a_{0}, & \left.a_{1}\right)
\end{array}\right.\right.\right.
$$

by its first-order necessary condition:

$$
\frac{\partial E[U]}{\partial a}=0
$$

However, the question is that the first-order necessary condition is not a sufficient condition of the incentive compatibility constraint. First, what satisfies $\mathrm{E}\left[\mathrm{U}(\mathrm{y}(\tilde{\mathrm{x}}), \quad \mathrm{a}] \geq \mathrm{E}\left[\mathrm{U}\left(\mathrm{y}(\tilde{\mathrm{x}}), \mathrm{a}^{\prime}\right]\right.\right.$ may be the boundary point, while $\mathrm{a}_{0}$ may not satisfy $\frac{\partial \mathrm{E}[\mathrm{U}]}{\partial \mathrm{a}}=0$ at all; second, even if the maximum value $\mathrm{E}[\mathrm{U}(\mathrm{y}(\tilde{\mathrm{x}}), \mathrm{a}] \geq \mathrm{E}[\mathrm{U}(\mathrm{y}(\tilde{\mathrm{x}})$, a'] has a solution of interior points, the points when $\frac{\partial \mathrm{E}[\mathrm{U}]}{\partial \mathrm{a}}=0$ may include partial maximum $\&$ minimum value points. Because $\frac{\partial \mathrm{E}[\mathrm{U}]}{\partial \mathrm{a}}=0$ and those points that can satisfy incentive constraint points may not be removed completely, the problem may exist for the incentive mechanism derived by the first-order condition method.

Of course, some conditions can be added appropriately to ensure $\frac{\partial E[\mathrm{U}]}{\partial \mathrm{a}}=0$, and these conditions are the sufficient conditions of $\mathrm{E}\left[\mathrm{U}(\mathrm{y}(\tilde{\mathrm{x}}), \mathrm{a}] \geq \mathrm{E}\left[\mathrm{U}\left(\mathrm{y}(\tilde{\mathrm{x}}), \mathrm{a}^{\prime}\right]\right.\right.$ at the same time. First, supposing $\mathrm{E}[\mathrm{U}(\mathrm{y}(\tilde{\mathrm{x}}), \mathrm{a}] \geq \mathrm{E}[\mathrm{U}(\mathrm{y}(\tilde{\mathrm{x}})$, a'] has the interior point solution, so the solution certainly meets $\frac{\partial \mathrm{E}[\mathrm{U}]}{\partial \mathrm{a}}=0$. If $\mathrm{E}[\mathrm{U}]$ is also a concave function of $a$, then, $\frac{\partial \mathrm{E}[\mathrm{U}]}{\partial \mathrm{a}}=0$ is a sufficient condition at the same time, that is to say, it needs:

$$
\int_{\alpha}^{\beta}\{u[y(x)]-a\} f_{a a}(x, a) d x \leq 0
$$

By the integration by parts, above formula is equivalent to:

$$
\int_{\alpha}^{\beta} F_{a a}(x, a) u^{\prime}[y(x)] y^{\prime}(x) d x \geq 0
$$

In addition, because $\mathrm{u}^{\prime}>0$, and in the monotonic likelihood condition, $\mathrm{y}^{\prime}(\mathrm{x})>0$,

$$
F_{a a}(x, a) \geq 0
$$

Thus, supposing the distribution function $F(x, a)$ is the convex function of $a$, and the monotonic likelihood ratio condition can be satisfied, then the rationality of the first-order condition can be guaranteed.

\section{Conclusions}

The local government is the represent of local environment and economical interests. As a unitary state, China may adopt the mechanism of consultation on the basis of equality between the Central Government and local government, or leverage for consultation and cooperation. As the local environmental quality is of externality, good environment in local administrative area can provide the external effect for the economy and society of this region, which is conducive to the local development. Currently China is standing in rapid development in economy and society, and its environmental legal systems are being established gradually. However, the environmental law enforcement demonstrates a barely satisfactory effect, and most of local governments don't take into serious considerations to fulfill the Central Government's environmental protection goals. Thus, great attention should be paid to the allocation of environmental right between the Central Government and local governments, governments and non-governmental organizations, and the public, so that the environmental management steps into a benign development track.

\section{References}

[1] Biemann, Frank (2002). The Case for A World Environment Organization. Environment Science and Policy for Sustainable Development, 43 (9): 22-31.

[2] Whalley, Hohn, Ben Zissimos (2002). An Internalization-Based World Environmental Organization. The World Economy, 25 (5): 619-642.

[3] Z Hu, C Wei, L Yao, C Li, Z Zeng (2016). Integrating Equality and Stability to Resolve Water Allocation Issues with A Multiobjective Bilevel Programming Model. Journal of Water Resources Planning \& Management, 142 (7): 1-12.

[4] A Dinar, RE Howitt (1997). Mechanisms for Allocation of Environmental Control Cost: Empirical Tests of Acceptability and Stability. Journal of Environmental Management, 49 (2): 183-203. 
[5] EJ Duckett (2006). Environmental Management Right-Sizing Environmental Controls. Chemical Engineering Progress, 102 (6): 43-47.

[6] Edeltraud Guenther, Jan Endrikat1, Thomas W. Guenther (2016). Environmental Management Control Systems: A Conceptualization and A Review of The Empirical Evidence. Journal of Cleaner Production, 136 (10): 147-171.

[7] Arika Virapongsea, Samantha Brooksc, Elizabeth Covelli Metcalfd (2016). A Social-Ecological Systems Approach for Environmental Management. Journal of Environmental Management, 178 (9): 83-91.

[8] Marilyn T. Lucas, Thomas G. Noordewier (2016). Environmental Management Practices and Firm Financial Performance: The Moderating Effect of Industry Pollution-Related Factors. International Journal of Production Economics, 175 (5): 2 4-34.
[9] Ralph Mastromonaco (2015). Do Environmental Right-to-Know Laws Affect Markets? Capitalization of Information in The Toxic Release Inventory. Journal of Environmental Economics and Management, 71 (5): 54-70.

[10] OECD (2001). Towards Sustainable Development. Environmental Indicators, Paris.

[11] Matthew Van Essena, Mark Walker (2017). A Simple Market-Like Allocation Mechanism for Public Goods. Games and Economic Behavior, 101 (1): 6-19.

[12] Guang-Ming Shia, Jin-Nan Wangb, Bing Zhangc, Zhe Zhangd, Yong-Liang Zhang (2016). Pollution Control Costs of a Transboundary River Basin: Empirical Tests of The Fairness and Stability of Cost Allocation Mechanisms Using Game Theory. Journal of Environmental Management, 177 (7): 145-152. 